Article

\title{
Genomic Regions Analysis of Seedling Root Traits and Their Regulation in Responses to Phosphorus Deficiency Tolerance in CSSL Population of Elite Super Hybrid Rice
}

\author{
Galal Bakr Anis ${ }^{1,2}$, Yingxin Zhang ${ }^{1}{ }^{\mathbb{D}}$, Huimin Wang ${ }^{3}$, Zihe $\mathrm{Li}^{1}{ }^{1}$, Weixun $\mathrm{Wu}^{1}{ }^{1}$, Lianping Sun ${ }^{1}$, \\ Aamir Riaz ${ }^{1}$, Liyong Cao ${ }^{1, *}$ and Shihua Cheng ${ }^{1, *}$ \\ 1 State Key Laboratory of Rice Biology, China National Rice Research Institute, Hangzhou 310006, \\ Zhejiang, China; galalanis5@gmail.com (G.B.A.); zyxrice@163.com (Y.Z.); lizihe0820@163.com (Z.L.); \\ wuweixun@caas.cn (W.W.); slphongjun8868@126.com (L.S.); aamirriaz33@gmail.com (A.R.) \\ 2 Rice Research and Training Center, Field Crops Research Institute, Agriculture Research Center, \\ Kafr Elsheikh 33717, Egypt \\ 3 Jiangxi Academy of Agricultural Sciences, Nanchang 210014, China; wxn6700@163.com \\ * Correspondence: caoliyong@caas.cn (L.C.); shcheng@mail.hz.zj.cn (S.C.); \\ Tel.: +86-571-63370329 (L.C. \& S.C.); Fax: +86-571-63370265 (L.C. \& S.C.)
}

Received: 22 February 2018; Accepted: 2 May 2018; Published: 14 May 2018

\begin{abstract}
Phosphorus (P) is the essential macro-element supporting rice productivity. Quantitative trait loci (QTL) underlying related traits at the seedling stage under two different phosphorus levels was investigated in rice using a population of 76 Chromosomal Sequence Substitution Lines (CSSLs) derived from a cross between the maintainer variety XieqingzaoB (P stress tolerant) and the restorer variety Zhonghui9308 (P stress sensitive); the parents of super hybrid rice Xieyou9308. A genetic linkage map with 120 DNA marker loci was constructed. At logarithmic odd (LOD) value of 2.0, a total of seven QTLs were detected for studied traits under two P levels and their relative ratio. The LOD values ranged from 2.00 to 3.32 and explaining $10.82 \%$ to $18.46 \%$ of phenotypic variation. Three QTLs were detected under low phosphorus $\left(\mathrm{P}^{-}\right)$, one under normal $\left(\mathrm{P}^{+}\right)$and three under their relative ratio $\left(\mathrm{P}^{-} / \mathrm{P}^{+}\right)$on the rice chromosomes $3,5,6,8$ and 10. No significant QTLs were found for shoot dry weight (SDW) and total dry weight (TDW). The pleiotropic QTLs influencing root number ( $q R N 5)$ and root dry weight ( $q R D W 5)$ as novel QTLs under $\mathrm{P}^{-}$level were detected near marker RM3638 on chromosome 5, which considered to directly contributing to phosphorus deficiency tolerance in rice. These QTLs need further analysis, including the fine mapping and cloning, which may use in molecular marker assisted breeding.
\end{abstract}

Keywords: rice; phosphorus deficiency; genomic regions; CSSLs; root traits

\section{Introduction}

Rice (Oryza sativa L.) is grown in many parts of the world and considered as a primary staple food source for more than half of the world's population. Therefore, rice plays an important role to boost the food security and poverty alleviation in rice-eating countries, although it is cultivated in areas with soil phosphorus deficiency [1]. Nitrogen $(\mathrm{N})$, phosphorus $(\mathrm{P})$ and potassium $(\mathrm{K})$ are the three most common and primary nutrients required for plant growth and development, which are applied to rice fields in the form of chemical fertilizers [2]. The limitation of soil fertility and high costs of fertilizers are the biggest challenges faced by the farmers in most of rice cultivated areas [3]. Phosphorus $(\mathrm{P})$ is fundamental to crop development because it's playing main roles as a component 
of many organic molecules, phospholipids and proteins [4,5]. Generally, phosphorus as one of the three nutrients added to soil because it is readily leached by soil particles [6]. Approximately $80 \%$ of phosphorus content in the soil can be fixed in non-available forms to plants [7]. Beside yield as the most important trait, studying of root growth parameters such as root length, root number, root dry weight, shoot dry weight and total dry weight under various stress conditions are the important traits in rice breeding programs. Most of the stresses in rice lead to changes in root system architecture and phosphorus $(\mathrm{P})$ deficiency is one of them [8-10]. Interestingly, P deficiency is one of the main limiting factors in rice production in many rice cultivated countries. Screening and developing rice genotypes that have the properties of phosphorus $(\mathrm{P})$ efficiency provide an alternative and promising solution to resolve this problem, through the utilization of those genotypes as parents in the rice breeding programs [11,12].

Genomic technologies, molecular markers as well as statistical methods had revolutionized the genetic analysis of plant breeding and provide valuable tools for identifying genomic regions influencing abiotic stresses such as phosphorus deficiency tolerant. These technologies have led to a growing understanding of the underlying processes behind plant responses to the P deficiency of molecules through the whole plant level [13]. Marker technologies and maps allow the quantitative trait loci (QTL), site genomic regions with positive effects on yield stability, or phosphorus deficiency tolerant under adverse environmental conditions [13]. Mapping Quantitative trait loci (QTL) are a powerful method of analysis to assign the positions of genes contributing to seedling root traits related to $\mathrm{P}$ deficiency tolerance in rice. Previous studies associated with $\mathrm{P}$ deficiency in rice seedling stage identified different QTLs and reported that a P deficiency is controlled by complex quantitative traits [14-19]. The genome mapping can be used to identify the QTLs associated with phosphorus deficiency traits, controlled by multiple genes and show the genetic characteristics of the quantitative properties [11,18,20-23]. A total of those studies investigated root traits performance under P deficient conditions $[14,18,24,25]$. Several QTLs for low phosphorus tolerance in rice has been detected on chromosomes 1, 2, 3, 4, 5, 6, 9, 10 and 12 [26]. PSTOL1 as a major candidate gene for phosphorus (P) deficiency was located on chromosome 12 of rice and cloned from $P$ deficiency tolerant rice variety Kasalath under name Pup $1[27,28]$. The information of loci associated with traits under phosphorus deficiency is important to develop the new rice varieties with the stress tolerance.

In our study, a rice population consisting of 75 CSSLs, derived from a cross between XieqingzaoB (P deficiency tolerance) and Zhonghui9308 (P deficiency susceptible), were used. This study investigated the effects of $\mathrm{P}$ deficiency treatment and detected quantitative trait loci (QTLs) for $\mathrm{P}$ deficiency traits at the seedling stages of rice. We examined the additive QTLs for P deficiency in root and shoot traits under two levels of phosphorus $\left(\mathrm{P}^{+}\right.$and $\left.\mathrm{P}^{-}\right)$using IciMapping (Wang 2009) approaches. These QTLs can be used in improving P deficiency tolerance of rice by MAS and the results will be helpful for understanding the molecular mechanisms under phosphorus deficiency conditions.

\section{Results}

\subsection{Phenotypic and Frequency Distribution of 75 CSSLs and Their Parents}

The phenotypic variation and distributions of six seedling traits of the two parents and the CSSL population under both deficient and normal P conditions are shown in Table 1 . The mean performance values of each parameter are given across treatments and separately for the normal and low phosphorus levels. Among the six studied traits at the seedling stage, the parent XieqingzaoB recorded higher mean performance values than those in Zhonghui9308 for all traits except shoot length trait under both P levels, indicating that XieqingzaoB was integrally more tolerant than Zhonghui9308 to phosphorus deficiency at rice seedling stage (Table 1 and Figure 1). Wide variations for all six seedling traits were observed under both the normal and low $\mathrm{P}$ treatments, and the transgressive segregations were positive under both $\mathrm{P}$ levels except root number $(\mathrm{RN})$ under normal $\mathrm{P}$ level. The kurtosis and skewness for the distributions of the studied six traits in the chromosomal segment substitution lines 
(CSSLs) population were less than unit except shoot dry weight (SDW) and total dry weight (TDW), suggesting that these traits near normal distributions and the data is suitable for quantitative trait loci analysis. Moreover, these traits illustrated frequency distribution, genetic characteristics of quantitative traits, existed transgressive segregation and polygenic inheritance (Figure 2). For analysis of variance, two-factor ANOVA (genotype and treatment) indicated that genotype, treatment, and genotype $\times$ treatment interaction were significantly different in CSSL population (Table 2). The effects of the genotypes and genotype-by-environment interaction were almost equally important for all traits except genotypes for the root number trait.

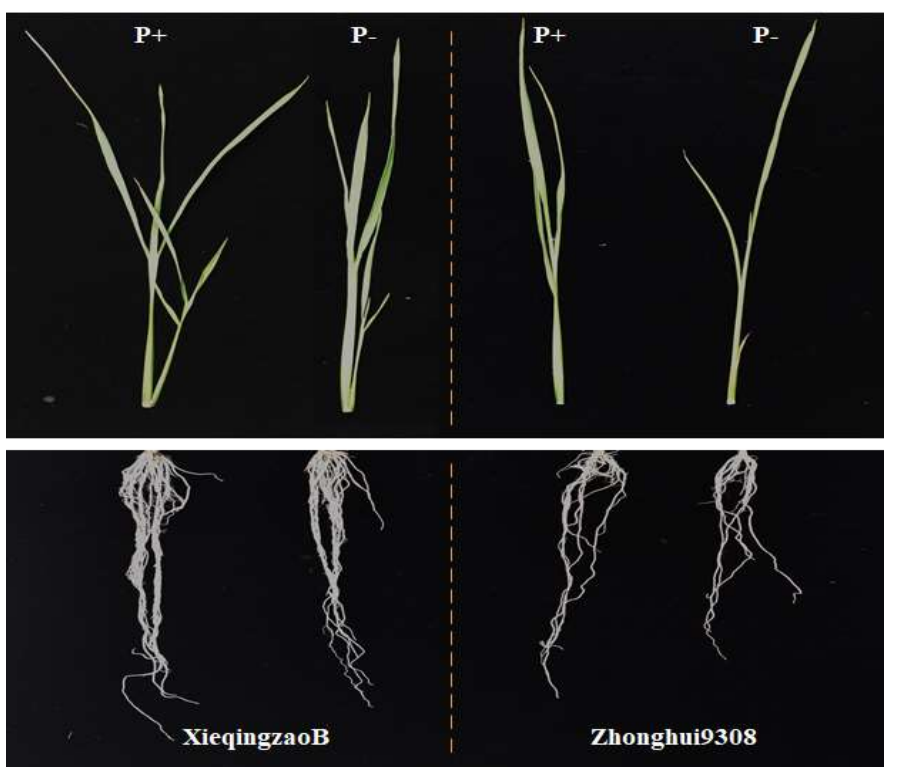

Figure 1. Phenotype of the rice parental lines XieqingzaoB and Zhonghui9308 after four weeks under hydroponic conditions, $\mathrm{P}^{+}$normal conditions and $\mathrm{P}^{-}$deficient conditions.

Table 1. Phenotypic variation for seedling root traits under both P levels in CSSLs population and their parents.

\begin{tabular}{|c|c|c|c|c|c|c|c|c|c|c|}
\hline \multirow{2}{*}{ Treat. } & \multirow{2}{*}{ Trait } & \multicolumn{2}{|c|}{ Parents } & \multirow{2}{*}{$p$-Value } & \multicolumn{6}{|c|}{ Chromosomal Segment Substitution Lines (CSSLs) } \\
\hline & & XieqingzaoB & Zhonghui9308 & & Min. & Max. & Mean & SD\% & Kurtosis & Skewness \\
\hline \multirow{6}{*}{$\begin{array}{l}\text { Normal } \\
\text { phosphorus } \\
\left(\mathrm{P}^{+}\right)\end{array}$} & SL & 20.68 & 21.67 & 0.172 & 16.52 & 27.82 & 21.06 & 2.02 & 0.79 & 0.12 \\
\hline & RL & 8.93 & 7.70 & 0.071 & 4.43 & 9.23 & 6.56 & 1.14 & -0.58 & 0.20 \\
\hline & $\mathrm{RN}$ & 9.00 & 7.17 & 0.022 & 5.00 & 8.67 & 6.18 & 0.80 & -0.19 & 0.47 \\
\hline & SDW & 86.43 & 83.83 & 0.007 & 55.38 & 104.8 & 80.91 & 10.64 & -0.25 & 0.27 \\
\hline & RDW & 37.22 & 28.00 & 3.710 & 18.33 & 39.0 & 26.59 & 5.13 & -0.46 & 0.64 \\
\hline & TDW & 123.65 & 111.83 & 0.000 & 82.01 & 142.1 & 107.51 & 14.65 & -0.47 & 0.48 \\
\hline \multirow{6}{*}{$\begin{array}{l}\text { Low phosphorus } \\
\qquad\left(\mathrm{P}^{-}\right)\end{array}$} & SL & 19.46 & 20.29 & 0.166 & 15.03 & 24.33 & 20.48 & 2.19 & -0.25 & -0.52 \\
\hline & RL & 7.54 & 6.34 & 0.071 & 4.37 & 10.33 & 7.62 & 1.08 & 0.39 & 0.07 \\
\hline & $\mathrm{RN}$ & 7.35 & 6.00 & 0.051 & 5.67 & 9.50 & 7.36 & 0.79 & -0.37 & 0.33 \\
\hline & SDW & 84.33 & 79.00 & 0.001 & 50.00 & 115.67 & 87.39 & 16.81 & -1.10 & -0.08 \\
\hline & RDW & 32.67 & 26.67 & 0.029 & 19.38 & 59.00 & 33.79 & 9.84 & -0.59 & 0.46 \\
\hline & TDW & 117.00 & 105.67 & 2.36 & 82.67 & 167.7 & 121.19 & 25.29 & -1.35 & 0.14 \\
\hline
\end{tabular}

Abbreviations: SL: Shoot length (cm); RL: Root length (cm); RN: Root number; SDW: Shoot dry weight (mg); RDW: Root dry weight (mg) and TDW: Total dry weight (mg). 

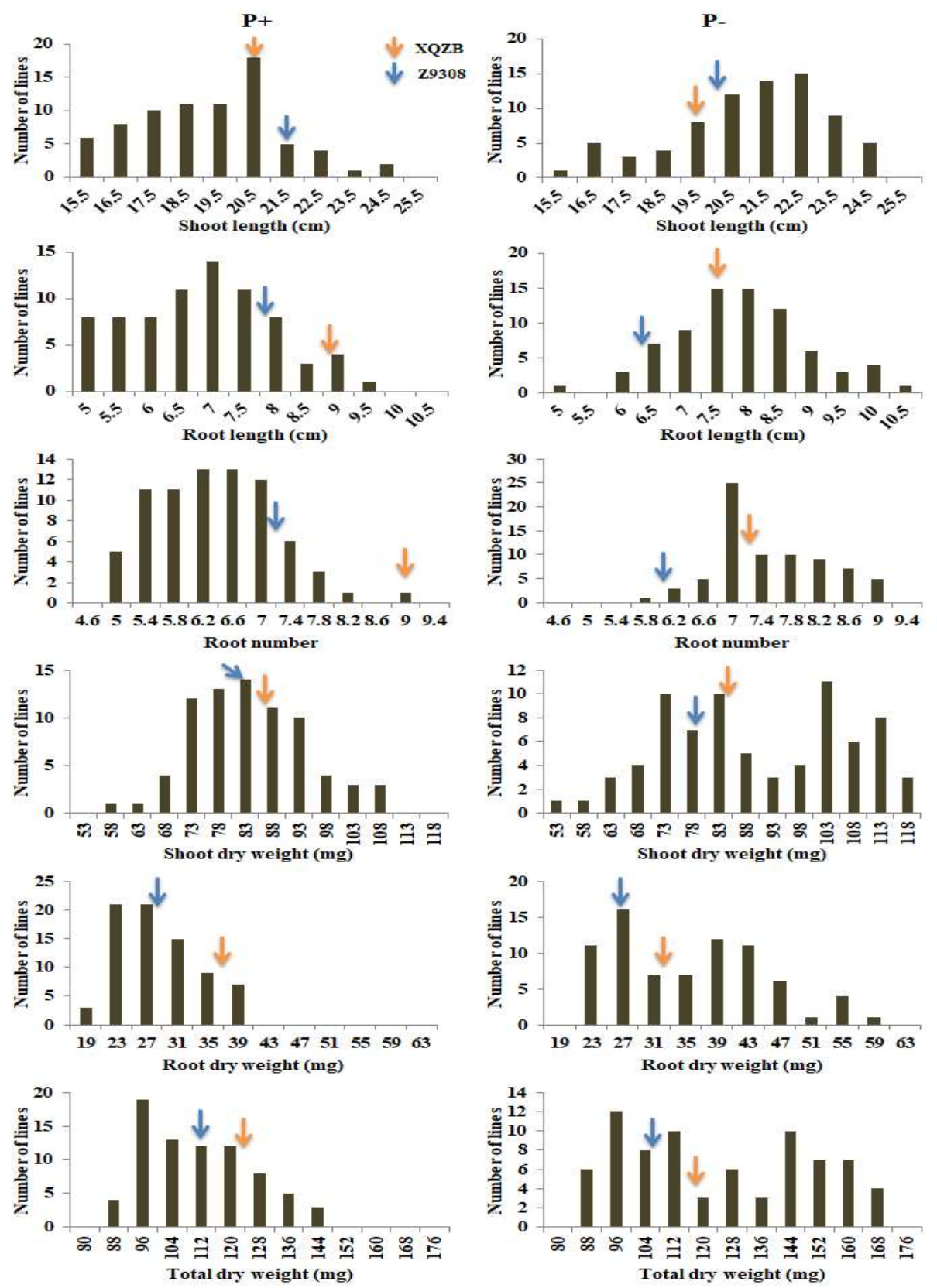

Figure 2. Distribution of mean values of 75 CSSLs and their parents for six seedling root traits under two phosphorus levels, normal $\left(\mathrm{P}^{+}\right)$and low $\left(\mathrm{P}^{-}\right)$. Red and blue arrows indicate the mean values for XieqingzaoB (XQZB) and Zhonghui9308 (Z9308), respectively. 
Table 2. Analysis of variance of six seedling root traits in the CSSL population of XieqingzaoB/Zhonghui9308.

\begin{tabular}{|c|c|c|c|c|}
\hline S.O.V & $d f$ & MS & $F$-Value & $p$-Value \\
\hline \multicolumn{5}{|c|}{ Shoot length (cm) } \\
\hline Genotype (G) & 74 & 14.92 & 17.01 & 0.01 \\
\hline Treatment $(\mathrm{T})$ & 1 & 25.61 & 29.31 & 0.34 \\
\hline $\mathrm{G} \times \mathrm{T}$ & 74 & 2.93 & 33.00 & 0.73 \\
\hline Error & 150 & 4.09 & & \\
\hline \multicolumn{5}{|c|}{ Root length $(\mathrm{cm})$} \\
\hline Genotype (G) & 74 & 2.26 & 13.06 & 0.02 \\
\hline Treatment (T) & 1 & 84.44 & 49.00 & 0.20 \\
\hline $\mathrm{G} \times \mathrm{T}$ & 74 & 2.72 & 16.60 & 0.48 \\
\hline Error & 150 & 1.18 & & \\
\hline \multicolumn{5}{|c|}{ Root number } \\
\hline Genotype (G) & 74 & 0.70 & 19.35 & 0.11 \\
\hline Treatment (T) & 1 & 102.80 & 28.25 & 0.00 \\
\hline $\mathrm{G} \times \mathrm{T}$ & 74 & 1.85 & 50.87 & 0.08 \\
\hline Error & 150 & 0.65 & & \\
\hline \multicolumn{5}{|c|}{ Shoot dry weight (mg) } \\
\hline Genotype (G) & 74 & 373.95 & 40.15 & 0.76 \\
\hline Treatment (T) & 1 & 3152.26 & 33.84 & 0.00 \\
\hline $\mathrm{G} \times \mathrm{T}$ & 74 & 417.90 & 44.87 & 0.27 \\
\hline Error & 150 & 113.21 & & \\
\hline \multicolumn{5}{|c|}{ Root dry weight (mg) } \\
\hline Genotype (G) & 74 & 76.92 & 498.22 & 0.00 \\
\hline Treatment (T) & 1 & 3889.58 & 100.23 & 0.00 \\
\hline $\mathrm{G} \times \mathrm{T}$ & 74 & 169.65 & 437.00 & 0.00 \\
\hline Error & 150 & 96.90 & & \\
\hline \multicolumn{5}{|c|}{ Total dry weight (mg) } \\
\hline Genotype (G) & 74 & 691.25 & 57.09 & 0.44 \\
\hline Treatment (T) & 1 & 14045.53 & 113.60 & 0.90 \\
\hline $\mathrm{G} \times \mathrm{T}$ & 74 & 1017.78 & 84.06 & 0.63 \\
\hline Error & 150 & 214.63 & & \\
\hline
\end{tabular}

\subsection{Correlation Coefficient Analysis among Seedling Root Traits}

In our investigation, we get insight in the phenotypic correlation coefficient analysis between the six seedling traits separately; one with line means from normal P and one with line means from low $\mathrm{P}$ and the results are presented in Table 3 . According to the results, significant positive correlation coefficients were observed between all studied traits under normal P. Similar correlations were also found under low P. These correlations ranged from 0.322 to 0.967 under normal $\mathrm{P}$, and from 0.242 to 0.971 under low P (Table 3). Under both the normal and low P treatments, TDW recorded the strongest correlations with SDW and RDW with values of 0.967 and 0.849 under normal $\mathrm{P}$ and 0.971 and 0.912 under low P, respectively. Simultaneously, a significant positive correlation was also observed in the SL trait between the normal P and low P unlike RN and RDW where had recorded significant negative correlations. 
Table 3. Correlation coefficient analysis among the studied traits under both the normal and low $\mathrm{P}$ treatments in the CSSLs.

\begin{tabular}{|c|c|c|c|c|c|c|c|c|c|}
\hline \multicolumn{10}{|c|}{ Low Phosphorus $\left(\mathrm{P}^{-}\right)$} \\
\hline \multirow{8}{*}{$\begin{array}{c}\text { Normal } \\
\text { Phosphorus }\left(\mathbf{P}^{+}\right)\end{array}$} & Traits & SL & RL & RN & SDW & RDW & TDW & Traits & \multirow{8}{*}{ 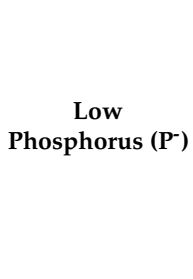 } \\
\hline & SL & $0.673^{* *}$ & $0.519^{* *}$ & $0.394 * *$ & $0.542 * *$ & $0.242 *$ & $0.454^{* *}$ & SL & \\
\hline & RL & $0.322^{* *}$ & -0.091 & $0.440^{* *}$ & 0.621 ** & $0.592 * *$ & 0.643 ** & RL & \\
\hline & RN & $0.398^{* *}$ & $0.441^{* * *}$ & $-0.449^{* * *}$ & $0.622 * *$ & $0.592 * *$ & $0.644^{* *}$ & RN & \\
\hline & SDW & $0.605^{* *}$ & $0.610^{\text {** }}$ & $0.577^{* *}$ & -0.061 & $0.786^{* *}$ & 0.971 ** & SDW & \\
\hline & RDW & $0.362 * *$ & 0.646 ** & $0.617^{* *}$ & $0.686^{* *}$ & $-0.458^{* *}$ & 0.912 ** & RDW & \\
\hline & TDW & $0.566^{* *}$ & $0.670^{* *}$ & $0.635^{* *}$ & $0.967 * *$ & $0.849^{* *}$ & -0.220 & TDW & \\
\hline & Traits & SL & RL & RN & SDW & RDW & TDW & Traits & \\
\hline \multicolumn{10}{|c|}{ Normal Phosphorus $\left(\mathrm{P}^{+}\right)$} \\
\hline
\end{tabular}

The data along the diagonal and shaded in black correspond to correlations between the traits under two P levels. The data above the diagonal correspond to correlations among traits under low $\mathrm{P}$, while the below ones under normal P. SL, shoot length, RL, root length, RN, root number, SDW, shoot dry weight, RDW, root dry weight, TDW, total dry weight. The asterisks * and ${ }^{* *}$ denote significance at the 0.05 and 0.01 probability levels, respectively.

\subsection{QTL Analysis for Seedling Root Traits under $P^{+}$and $P^{-}$Levels and Their Relative Ratio}

A total of seven QTLs were detected with significant LOD values for each trait under the two $P$ levels and their ratio (Figure 3). Among six seedling traits, no significant QTLs were found for shoot dry weight (SDW) and total dry weight (TDW). For seven QTLs were detected under $\mathrm{P}^{+}, \mathrm{P}^{-}$and $\mathrm{P}^{-} / \mathrm{P}^{+}$, the LOD values ranged from 2.00 to 3.32 (Table 4). QTL explained the phenotypic variance ranged from $10.82 \%$ to $18.46 \%$. Three QTLs were detected under $\mathrm{P}^{-}$, one under $\mathrm{P}^{+}$and three under $\mathrm{P}^{-} / \mathrm{P}^{+}$ratio. The QTLs were distributed on the rice chromosomes 3, 5, 6, 8 and 10; most of them are one QTL on chromosome 3, two QTLs on chromosome 5, two QTL on chromosome 6, one QTL on chromosome 8 and one QTL on chromosome 10 were detected (Figure 3). Two QTLs of shoot length (SL) were detected on chromosomes 6 and 8. One QTL, qSL6 was detected near marker InD90 under normal phosphorus $\left(\mathrm{P}^{+}\right)$level, and the other QTL, $q S L 8$ was detected near the marker RM337 under $\mathrm{P}^{-} / \mathrm{P}^{+}$ratio. The explained phenotypic variance and LOD scores of two QTL were $16.94 \%$ and 3.02 and $18.46 \%$ and 3.32, respectively. There was only one QTL ( $q R L 6)$ for root length (RL) that was mapped under $\mathrm{P}^{-} / \mathrm{P}^{+}$ratio by IciMapping. The QTL $q R L 6$ was located on chromosome 6 near the marker InD90, with a LOD score of 2.31 that explained $16.07 \%$ of phenotypic variance which was the same region harboring a QTL for shoot length under normal phosphorus $\mathrm{P}^{+}$level. The positive allele for $q R L 6$ was contributed by XieqingzaoB and this contributed to increase the root length trait. For root number trait, only one QTL ( $q R N 5)$ under low phosphorus $\left(\mathrm{P}^{-}\right)$was identified on chromosome 5 in the marker RM3638 with LOD value of 2.21 and explaining phenotypic variation of $12.71 \%$. The positive allele for $q R N 5$ was contributed by XieqingzaoB. Concerning the QTLs for root dry weight (RDW), three QTLs for this trait were revealed under two different phosphorus $(\mathrm{P})$ levels. Under low phosphorus $\left(\mathrm{P}^{-}\right)$level, two QTLs were detected. One QTL ( $q R D W 3$ ) controlling root dry weight was located on chromosome 3 in the marker interval InD36, with a LOD score of 2.00 that explained $10.82 \%$ of phenotypic variance. Under the same P level, another QTL ( $q R D W 5$ ) was detected on chromosome 5 which was the same region harboring a QTL for the root number under $\mathrm{P}^{-}$with explaining about $12.66 \%$ phenotypic variation and LOD score of 2.37 . Simultaneously, one QTL ( $q R D W 10$ ) was located on chromosome 10 near marker InD133 under $\mathrm{P}^{-} / \mathrm{P}^{+}$ratio with a LOD value of 2.18 that explained $12.52 \%$ of phenotypic variance. The additive effects were positive in $q R D W 5$ and $q R D W 10$, implying the alleles were derived from the XieqingzaoB parent line increased the root dry weight. On the other hand, the additive effect was negative in $q R D W 3$ indicating that, the allele derived from Zhonghui9308 of this QTL was responsible for decreasing root dry weight in populations. 


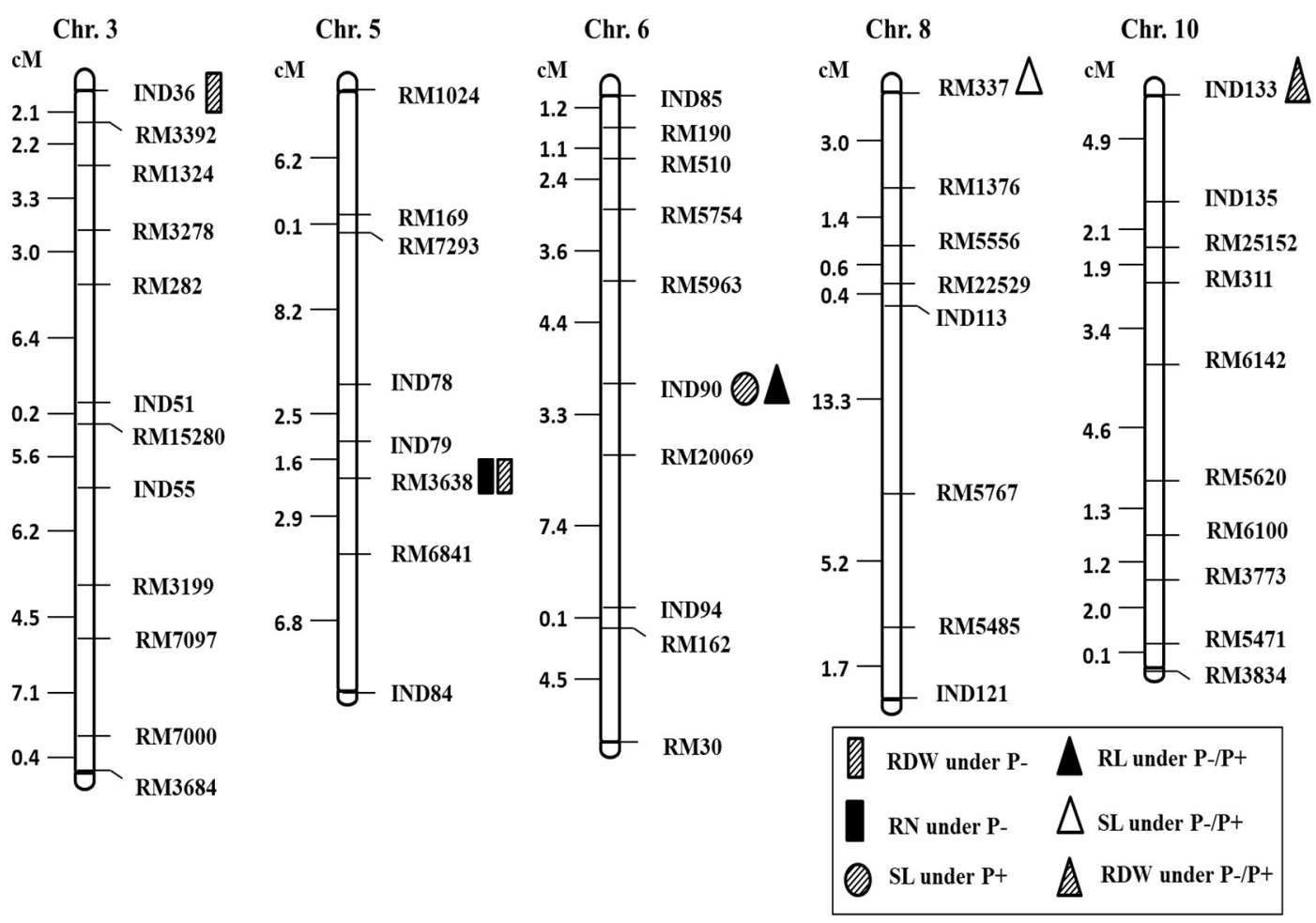

Figure 3. Chromosomal location of putative QTLs for root dry weight (RDW), root number (RN), shoot length (SL) and root length (RL) under both the normal $\left(\mathrm{P}^{+}\right)$and low $\left(\mathrm{P}^{-}\right)$phosphorus and their ratio $\left(\mathrm{P}^{-} / \mathrm{P}^{+}\right)$conditions.

Table 4. Putative QTLs controlling the seedling root traits detected in the Chromosomal Sequence Substitution Lines (CSSLs) population.

\begin{tabular}{cccccccccc}
\hline Trait & Chr. & Marker & QTL & Treatment & LOD Value & Additive Effect & PVE\% & M (QQ) & M (qq) \\
\hline SL & 6 & InD90 & $q S L 6$ & $\mathrm{P}^{+}$ & 3.02 & 2.57 & 16.94 & 26.10 & 20.92 \\
SL & 8 & RM337 & $q S L 8$ & $\mathrm{P}^{-} / \mathrm{P}^{+}$ & 3.32 & -0.11 & 18.46 & 0.76 & 0.97 \\
RL & 6 & InD90 & $q R L 6$ & $\mathrm{P}^{-} / \mathrm{P}^{+}$ & 2.31 & 0.68 & 16.07 & 2.74 & 1.04 \\
RN & 5 & RM3638 & $q R N 5$ & $\mathrm{P}^{-}$ & 2.21 & 0.62 & 12.71 & 8.54 & 7.29 \\
RDW & 3 & InD36 & $q R D W 3$ & $\mathrm{P}^{-}$ & 2.00 & -6.13 & 10.82 & 22.51 & 34.77 \\
RDW & 5 & RM3638 & $q R D W 5$ & $\mathrm{P}^{-}$ & 2.37 & 8.01 & 12.66 & 48.95 & 32.94 \\
RDW & 10 & InD133 & $q R D W 10$ & $\mathrm{P}^{-} / \mathrm{P}^{+}$ & 2.18 & 0.81 & 12.52 & 2.92 & 1.30 \\
\hline
\end{tabular}

\subsection{Seedling Root Traits in CSSLs under P deficiency}

Using 75 CSSL populations, two co-located additive QTLs associated with root number ( $q R N 5)$ and root dry weight ( $q R D W 5$ ) when plants were exposed to $\mathrm{P}^{-}$deficiency. Four lines, CSSL-34, CSSL-36, CSSL-39 and CSSL-69 are harboring these QTLs and each carry an introgression in this region and carry a common XieqingzaoB derived segment on the long arm of chromosome 5 (Figure 4A). To inform the root behavior of these lines under $\mathrm{P}^{-}$deficiency compared to the parental lines, an additional experiment for 40 days was done under $\mathrm{P}^{-}$deficiency. Therefore, the data presented in (Figure 4C-E) were taken from 40 day old seedlings under phosphorus deficient conditions. These four lines showed significantly higher results in root traits compared with Zhonghui9308 as a genetic background parent (Figure 4B). The candidate region was delimited between InD79 and RM6841 as neighboring markers of these QTLs on the long arm of chromosome 5 (Figure 4A), and corresponded to the QTL detected in the CSSL population. The physical length of the candidate region was approximately $4.5 \mathrm{cM}$. Concerning the three root traits, root length, root number and root dry weight, the four CSSLs gave significantly higher compared with Zhonghui9308 under $\mathrm{P}^{-}$deficiency and was similar to that of the corresponding genetic background, Zhonghui9308 (Figure 4C-E). 


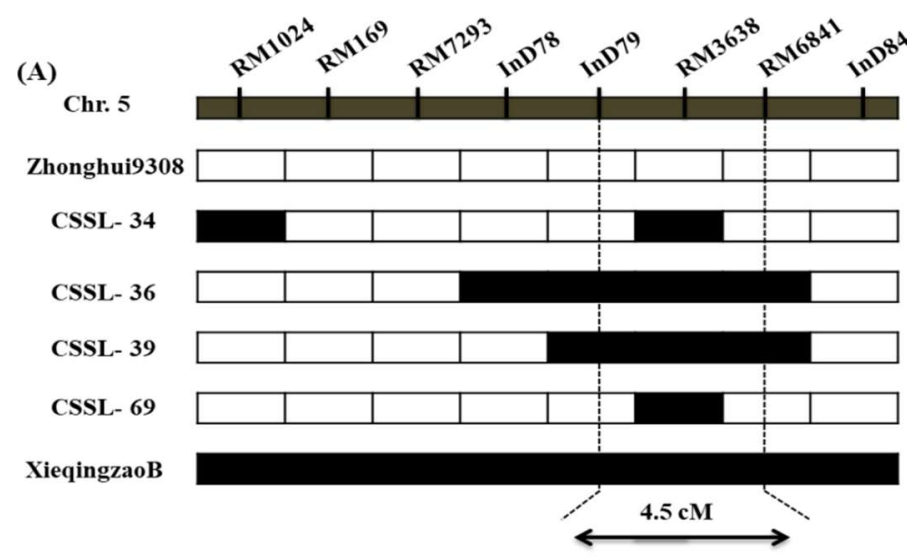

(B)
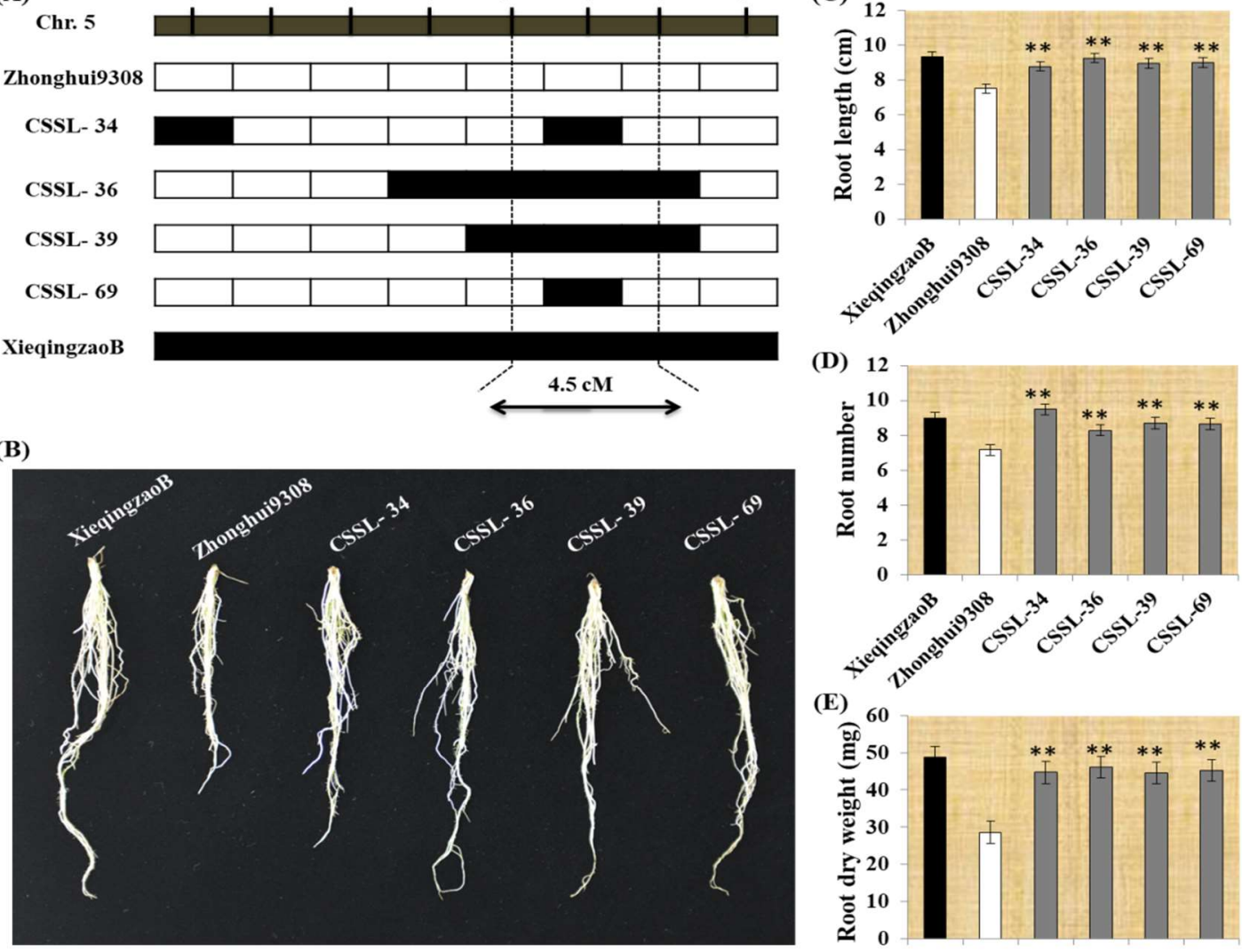

(D) 12

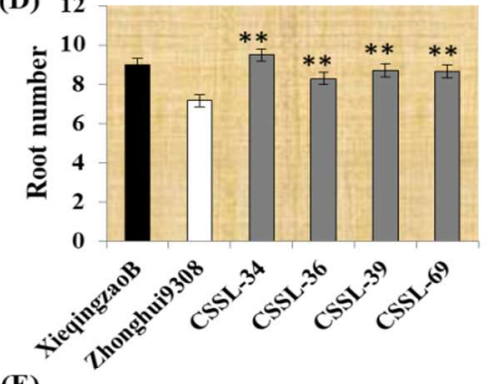

(E)

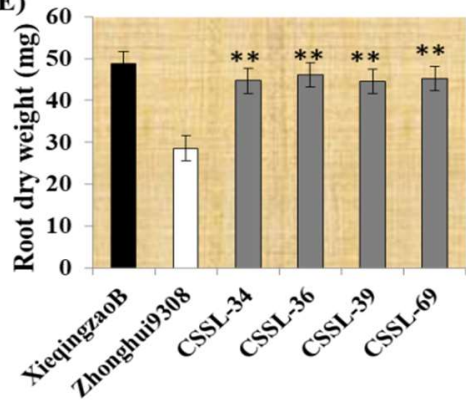

Figure 4. Graphical genotypic and phenotypic of CSSL-34, CSSL-36, CSSL-39 and CSSL-69 and their parents. (A) Putative QTL region for root number and root dry weight under P deficiency on rice chromosome 5. (B) Phenotypic variation between CSSLs and parents. (C-E) Measurements of root length, root number and root dry weight of XieqingzaoB, Zhonghui9308 and CSSL lines. The asterisks represent statistical significance between CSSLs and Z9308, determined by a student's $t$-test $(* * P<0.01)$.

\section{Discussion}

Quantitative trait loci (QTL) mapping is a powerful tool for genetic analysis of complex quantitative characters and a good way to detect the genes contributing to root seedling traits related to phosphorus deficiency tolerance in rice $[18,22]$. Detection of QTLs for seedling traits, like root length, root number, root dry weight and shoot dry weight can give novel insights into crop breeding to tolerate biotic and abiotic stresses [29]. Numerous investigations have been carried out to identify the QTLs for root traits associated with different phosphorus $(\mathrm{P})$ levels using various mapping populations [11,14-18,21-23,30-32]. By using 271 introgression lines of Yuefa/IRAT109 at the seedling stage, Li et al. [18] detected 11 additive QTLs and 15 pairs of epistatic QTLs under P deficiency, while seven additive QTLs and nine pairs of epistatic QTLs were identified under P-sufficiency condition. In our investigation, to understand the genetic basis and identify the QTLs associated with seedling growth traits, we evaluated 75 CSSLs previously developed from XieqingzaoB/Zhonghui9308 under two phosphorus $\left(\mathrm{P}^{+}\right.$and $\left.\mathrm{P}^{-}\right)$levels. The lines utilized in present study were homozygous with segment from the donor parent XQZB. The parent XieqingzaoB recorded higher mean performance values than those in Zhonghui9308 for all traits except shoot length trait under both P levels, indicating 
that XieqingzaoB was integrally more tolerant than Zhonghui9308 to phosphorus deficiency at rice seedling stage consistent with previous findings [23]. Based on the traits data, we performed QTL analysis for six seedling traits using 87 SSR and 33 InDel markers. Each line was genetically fixed and had the genetic background of XieqingzaoB. Furthermore, the transgressive segregation was observed for most of the studied traits (Figure 2) indicating that the donor parent (XieqingzaoB) carried favorable genes of seedling traits under phosphorus deficiency.

Rice genotypes differed in their response to phosphorus deficiency, and the observed differences were attributed to genetic variation. Consequently, shoot length is an important indicator of the plant response to $\mathrm{P}^{-}$related stress. Two QTLs of shoot length (SL) were detected on chromosomes 6 and 8, whereby $q S L 6$ was located near the InD90 marker under normal phosphorus $\left(\mathrm{P}^{+}\right)$level, and $q S L 8$ was detected near the marker RM337 under $\mathrm{P}^{-} / \mathrm{P}^{+}$ratio. The explained phenotypic variation of the two QTLs was $16.94 \%$ and $18.46 \%$, respectively. By using DH population of CT9993 $\times$ IR62266 cross, Kanbar et al. [33] identified the QTL associated with root and related traits and found two QTLs (qpht8-1, qpht8-2) for plant height in chromosome 8 with the respective LOD values of 3.20 and 2.45 and explained phenotypic variance of $12.6 \%$ and $8.5 \%$. Wang et al. [34] performed the QTL analyses associated with rice root traits in hydroponic conditions using 215 recombinant inbred lines derived from the same parents (ZQXB and Z9308) as those used in the present study, and identified three QTLs ( $q P H 7, q P H 8$ and $q P H 10)$ affecting plant height. Lin et al. [19] evaluated a set of recombinant inbred lines (RILs) for five seedling growth traits that emerge in $\mathrm{P}^{-}$deficient conditions. The authors detected twenty QTLs for seedling growth response to P deficiency on chromosomes 1, 4, 5, 7, 8, 9, 11 and 12, none of which correspond to the QTLs detected in this investigation. This discrepancy could be due to the differences in the parent cultivar combinations or variations in culture conditions. In a similar study of recombinant inbred line (RIL) population derived from the super hybrid rice XQZB/Z9308, in which effects of two nitrogen levels were examined, Feng et al. [35] detected QTLs for plant height under both nitrogen levels on chromosomes 6 , which explained $15.85 \%$ and $13.14 \%$ of the observed phenotypic variance. Root length is the most important trait for P deficiency because roots provide an interface between the plant system and various soil stresses. In our investigation, one QTL (qRL6) for root length was detected under $\mathrm{P}^{-} / \mathrm{P}^{+}$ratio on chromosome 6 near the marker InD90, with an LOD score of 2.31 , which explained $16.07 \%$ of the observed phenotypic variance. The QTL $q S L 6$ for shoot length under normal phosphorus $\mathrm{P}^{+}$level was located in the same region. The positive allele for $q R L 6$ was contributed by XieqingzaoB, which accentuated the root length trait. Niu et al. [36] reported that, phosphorus deficiency in rice leads to increased root length. Similarly, $q R E P-6$, a root elongation QTL under P- deficient conditions was mapped on chromosome $6[18,21,37]$. Moreover, $q R L 6.1$ as a major QTL for root length under growth conditions characterized by different nitrogen concentrations at the seedling stage was mapped by Obara et al. [38]. However, it is noteworthy that the QTLs identified by different authors were not located in the region where Zhang et al. [39] detected three QTLs for root length ( $q R R L 7, q R R L 11$ and $q R R L 12)$ under P-deficient growth conditions, for which an LOD value of 2.91, 2.16 and 2.30 was reported, along with $13.3 \%, 10.7 \%$ and $10.3 \%$ total phenotypic variation explained, respectively. In addition, Zhang et al. [23] mapped two QTLs, qTPDE7.1 and qTPDE7.1 for root length under P-deficient conditions at the tillering stage. Wang et al. [34] performed QTL ( $q R L 7$ ) on chromosome 7 between markers RM3859 and RM214, with 18.14-18.36\% phenotypic variance explained. Previous findings suggest that the number of roots is the most important growth factor for ensuring that the plant obtains the required nutrients from soil, such as P, especially when subjected to environmental stresses [40]. When examining the number of roots as a specific trait, only one QTL ( $q R N 5)$ was detected under low phosphorus $\left(\mathrm{P}^{-}\right)$conditions. It was located on chromosome 5 near the marker RM3638 with an LOD value of 2.21 and $12.71 \%$ phenotypic variation explained. It is noteworthy that, one QTL for root dry weight ( $q R D W 5)$ under the same P level was also identified in this region. The correlations between these two QTLs ( $q R N 5$ and $q R D W 5$ ) were statistically significant irrespective of the $\mathrm{P}$ level, indicating that these traits promote phosphorus deficiency tolerance in rice cultivars. $q R N 5$ and $q R D W 5$ are novel QTLs for P deficiency that have not been reported in 
extant studies, in which no QTLs for these traits have been found in this region. Li et al. [18] detected two QTLs ( $q R N 4$ and $q R N 8)$ for root number under P-deficient growth conditions. For the root dry weight (RDW), two QTLs were detected in plants grown in low phosphorus $\left(\mathrm{P}^{-}\right)$conditions. One QTL ( $q R D W 3$ ) was detected on chromosome 3 near the marker InD36, accounting for $10.82 \%$ of the observed phenotypic variance, while the other QTL ( $q R D W 5$ ) was identified on chromosome 5, near the marker RM3638. In this region, a QTL for the number of roots as a function of the P level was identified, which explained about $12.66 \%$ of the total phenotypic variation. On the other hand, one QTL ( $q$ RDW10) was identified on chromosome 10 near the marker InD133 under $\mathrm{P}^{-} / \mathrm{P}^{+}$ratio, accounting for $12.52 \%$ of the total phenotypic variance. Some of these QTLs related to the RDW trait were new, while other were matched to the QTLs of RDW and related traits reported in the previous studies.

The application of QTL mapping for low phosphorus tolerance may greatly facilitate improvement of P deficiency tolerance in rice. We considered the QTLs identified on chromosome 5 to be the most effective because these QTLs were detected under P deficiency level with positive additive effect. Between the secondary physiological indices of phosphorus deficiency, the root number and root dry weight are more important than others. The QTLs, $q R D W 5$ and $q R N 5$ as novel QTLs located in the same region, indicate the strong relationship between these traits especially under $\mathrm{P}$ deficiency and their ability to increase root system may contribute to $P$ deficiency tolerance. Out of 75 CSSLs, four lines CSSL-34, CSSL-36, CSSL-39 and CSSL-69 each carry an introgression in this region on chromosome 5, and all had significantly root length, root number and root dry weight than Zhonghui9308 when grown under P deficiency (Figure 4C-E). These lines would be good to select for further study on the basis of a genetic map of the 75 chromosome segment substitution lines. In conclusion, the detection of new QTLs associated with P deficiency tolerance will give confirmed information for a genetic basis and functional analysis of rice $\mathrm{P}^{-}$tolerance, because they were identified in the CSSL population derived from two different parents. The molecular markers that are nearest to the QTLs will be useful for Marker Assisted Selection (MAS) to develop new rice varieties/lines with a high level of P deficiency tolerance in rice breeding program. In addition, the $\mathrm{P}$ deficiency tolerance lines may be used as new materials for rice breeding program.

\section{Materials and Methods}

\subsection{Plant Materials}

A hybrid population, Chromosomal Segment Substitution Lines (CSSLs) derived from a cross between the $\mathrm{P}$ stress tolerant variety XieqingzaoB (maintainer) and the $\mathrm{P}$ stress sensitive variety Zhonghui9308 (restorer) as parental lines for super hybrid rice (Xieyou9308) in China. This CSSLs population consisted of 76 lines carrying XieqingzaoB chromosomal segments on a genetic background of Zhonghui9308. The CSSL populations were developed as shown in Figure 5. The substituted chromosome segments covered most of the 12 chromosomes by 76 CSSLs. As one line was removed from this population for the lack of seeds, 75 lines plus their parents were used in this study. 


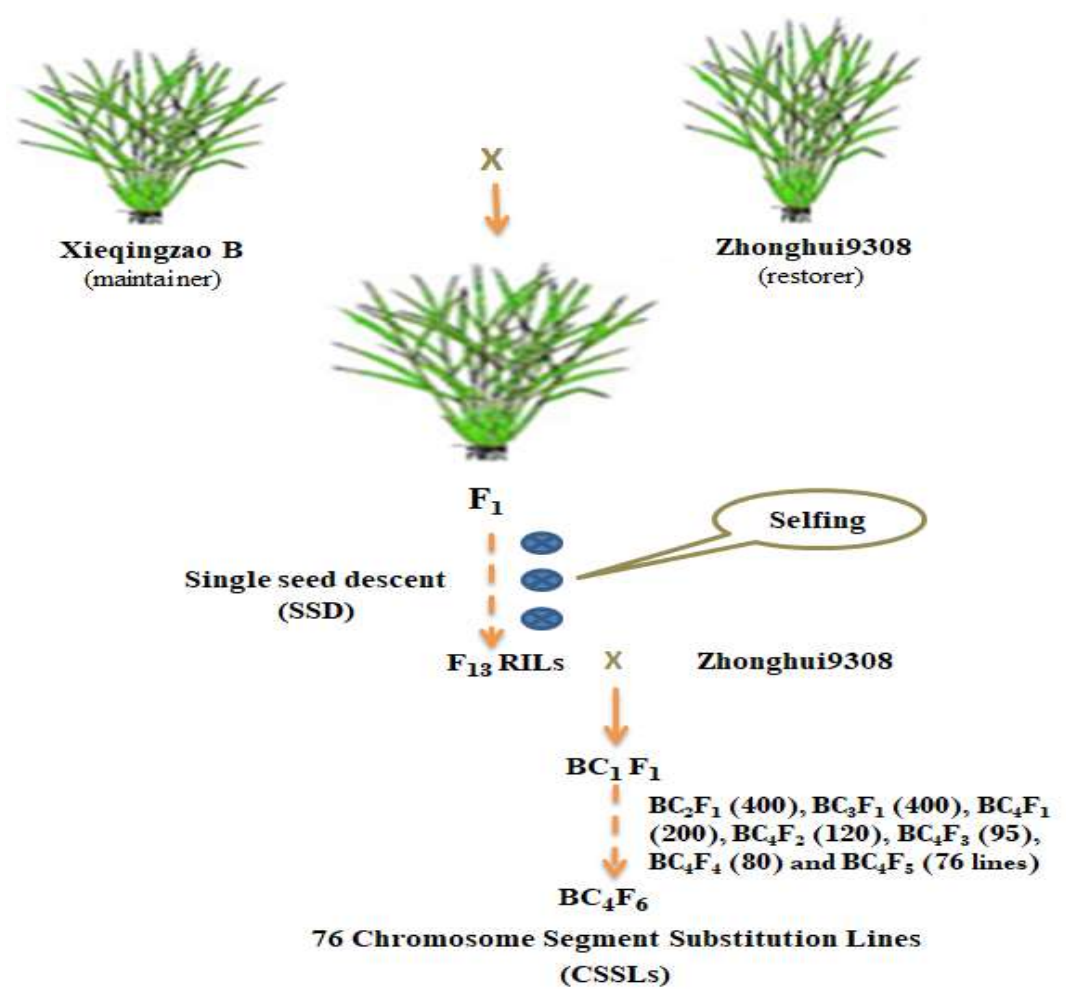

Figure 5. Crossing scheme for developing the 76 chromosome segment substitution lines (CSSLs).

\subsection{Hydroponic Experiment}

Seeds of 75 Chromosomal Segment Substitution Lines (CSSLs) and two parents were soaked for three days at $28{ }^{\circ} \mathrm{C}$ in water. Fifteen germinated seeds were sown on foam plates floated in pools and grown for one week before being moved to the containers. The experiment was conducted in the greenhouse condition at China National Rice Research Institute (CNRRI) at Hangzhou, China, from March 2017 to January 2018. The experiment design consisted of randomized complete blocks with three replications, five plants for each replicate. During the experiment, the plants were raised under the following conditions: temperature $30 \pm 3 / 21 \pm 2{ }^{\circ} \mathrm{C}$ day/night, relative humidity $70 \%$ and natural daylight. The nutrient solution was used according to Yoshida [41] with some modifications. The culture solution was prepared in distilled water. The nutrient solution was renewed weekly, and the normal culture solution was mixture of $(\mathrm{mg} / \mathrm{L}) ; 48.2\left(\mathrm{NH}_{4}\right)_{2} \mathrm{SO}_{4}, 59.9 \mathrm{Ca}\left(\mathrm{NO}_{3}\right)_{2}, 24.8 \mathrm{KH}_{2} \mathrm{PO}_{4}$, $18.5 \mathrm{KNO}_{3}, 15.9 \mathrm{~K}_{2} \mathrm{SO}_{4}$, and $65.9 \mathrm{MgSO}_{4}$ and $1 \mathrm{~mL} / \mathrm{L}$ Fe-EDTA, $\mathrm{H}_{3} \mathrm{BO}_{3}, \mathrm{CuSO}_{4} \cdot 5 \mathrm{H}_{2} \mathrm{O}, \mathrm{ZnSO}_{4} \cdot 7 \mathrm{H}_{2} \mathrm{O}$, $\mathrm{MnCl}_{2} \cdot 4 \mathrm{H}_{2} \mathrm{O}$, and $\mathrm{H}_{2} \mathrm{MoO}_{4} \cdot \mathrm{H}_{2} \mathrm{O}$. For the low phosphorus treatment, the $\mathrm{KH}_{2} \mathrm{PO}_{4}$ concentration decreased to $0.32(\mathrm{mg} / \mathrm{L})$.

\subsection{Phenotypic Investigation}

The growth parameters for 75 CSSLs and the two parents were measured after four weeks from the beginning of the low $\mathrm{P}$ treatment. Plants were sampled for trait measurements and genotypic analysis. After they had been sampled, the total roots were separated from the shoot base and shoot length (SL), root length (RL) and root number (RN) were investigated manually, while shoots and roots were over dried at $70{ }^{\circ} \mathrm{C}$ until a constant weight to evaluate shoot dry weight (SDW), root dry weight (RDW) and total dry weight (TDW). The phosphorus treatments were marked $\mathrm{P}^{+}, \mathrm{P}^{-}$and $\mathrm{P}^{-} / \mathrm{P}^{+}$for control level, low level and their relative ratio, respectively. All the traits investigated in this study were summarized in Table 5. 
Table 5. Summary of the investigated six seedling traits in this study.

\begin{tabular}{lccc}
\hline \multicolumn{1}{c}{ Trait } & Abbreviations & Unit & Trait Measurements \\
\hline Shoot length & SL & $\mathrm{cm}$ & Measured with a ruler \\
Root length & RL & $\mathrm{cm}$ & Measured with a ruler \\
Root number & RN & number & Counted manually \\
Shoot dry weight & SDW & $\mathrm{mg}$ & Dried and weighted using a balance $(1 / 1000 \mathrm{~g})$ \\
Root dry weight & RDW & $\mathrm{mg}$ & Dried and weighted using a balance $(1 / 1000 \mathrm{~g})$ \\
Total dry weight & TDW & $\mathrm{mg}$ & SDW + RDW \\
\hline
\end{tabular}

\subsection{QTL Mapping and Data Analysis}

A total of six phenotypic seedling traits (Table 1) represented by the means values for each genotype, were used for phenotypic and QTL analysis. Statistical and phenotypic correlation coefficient analyses were calculated with SAS software version 9.2. The relative values under low phosphorus $\left(\mathrm{P}^{-}\right)$ and corresponding value under normal $\left(\mathrm{P}^{+}\right)$were calculated for the QTL analysis. In our investigation, we carried out 87 SSR and 33 InDel markers, which were distributed along the rice genome according to previously reported linkage maps, and known polymorphisms between the parents, were used to determine the genotype of the CSSL populations. QTL analysis was performed with the IciMapping 4.0 (Wang, 2009) approaches. It was considered as a major effect QTL when its LOD was larger than 2.0. QTLs were named according to standard conventions of nomenclature (McCouch 2008).

\section{Conclusions}

Phosphorus $(\mathrm{P})$ is an essential plant nutrient for rice growth and phosphorus deficient stress for rice occurs frequently and its depletion causes limit rice growth, agronomical loss and reduce yields. In this study and by using 75 CSSLs derived from XieqingzaoB/Zhonghui9308, a total of seven QTLs were detected for seedling root traits under normal phosphorus $\left(\mathrm{P}^{+}\right)$, low phosphorus $\left(\mathrm{P}^{-}\right)$and their relative ratio $\left(\mathrm{P}^{-} / \mathrm{P}^{+}\right)$. Three QTLs were detected under $\mathrm{P}^{-}$, one under $\mathrm{P}^{+}$and three under $\mathrm{P}^{-} / \mathrm{P}^{+}$ ratio on the rice chromosomes 3, 5, 6, 8 and 10. Two QTLs influencing root number (qRN5) and root dry weight ( $q R D W 5$ ) as novel QTLs under $\mathrm{P}^{-}$deficiency conditions and not previously reported. These QTLs are valuable for future map-based cloning, which may use in molecular marker assisted breeding for developing new rice varieties/lines tolerant to phosphorus deficiency.

Author Contributions: Y.Z., S.C., L.C. conceived and designed the experiments. Y.Z., W.W., L.S. prepare materials. G.B.A. conducts the experiment. G.B.A., W.W., H.W., Z.L., L.S., A.R. acquisition of data. G.B.A., Y.Z. analysis and interpretation of data. G.B.A. drafting of manuscript. G.B.A., Y.Z., W.W., H.W., Z.L., L.S., A.R., S.C., L.C. revised and approved the manuscript.

Acknowledgments: This work was supported by the National Rice Technology System (CARS-01), the Natural Science Foundation of China (31521064), the National Key Transform Program (2016ZX08001-002), and the Super Rice Breeding Innovation Team and Rice Heterosis Mechanism Research Innovation Team of Chinese Academy of Agricultural Sciences Innovation Project (CAAS-ASTIP-2013-CNRRI).

Conflicts of Interest: The authors declare no conflict of interest.

\section{References}

1. Ismail, A.M.; Heuer, S.; Thomson, M.J.; Wissuwa, M. Genetic and genomic approaches to develop rice germplasm for problem soils. Plant Mol. Biol. 2007, 65, 547-570. [CrossRef] [PubMed]

2. De Datta, S.K. Principles and Practice of Rice Production; John Wiley and Sons: Singapore, 1981; pp. $348-419$.

3. Septiningsih, E.M.; Pamplona, A.M.; Sanchez, D.L.; Neeraja, C.N.; Vergara, G.V.; Heuer, S.; Ismail, A.M.; Mackill, D.J. Development of submergence-tolerant rice cultivars: The Sub1 locus and beyond. Ann. Bot. 2009, 103, 151-160. [CrossRef] [PubMed]

4. Lea, P.J.; Miflin, B.J. Nitrogen assimilation and its relevance to crop improvement. Ann. Plant Revi. 2010, 42, 1-40.

5. Cheng, L.Y.; Bucciarelli, B.; Shen, J.B.; Allan, D.; Vance, C.P. Update on white lupin cluster root acclimation to phosphorus deficiency. Plant Physiol. 2011, 156, 1025-1032. [CrossRef] [PubMed] 
6. Yan, X.L.; Wu, P.; Ling, H.Q.; Xu, G.H.; Xu, F.S.; Zhang, Q.F. Plant nutriomics in China: An overview. Ann. Bot. 2006, 98, 473-482. [CrossRef] [PubMed]

7. White, P.J.; Hammond, J.P. Phosphorus nutrition of terrestrial plants. In The Ecophysiology of Plant-Phosphorus Interactions; White, P.J., Hammond, J.P., Eds.; Springer: Dordrecht, The Netherlands; pp. 51-81.

8. Lambers, H.; Shane, M.W.; Cramer, M.D.; Pearse, S.J.; Veneklaas, E.J. Root structure and functioning for efficient acquisition of phosphorus: Matching morphological and physiological traits. Ann. Bot. 2006, 98, 693-713. [CrossRef] [PubMed]

9. Lynch, J.P. Root phenes for enhanced soil exploration and phosphorus acquisition: Tools for future crops. Plant Physiol. 2011, 156, 1041-1049. [CrossRef] [PubMed]

10. Hufnagel, B. Duplicate and conquer: Multiple homologs of PHOSPHORUS-STARVATION TOLERANCE1 enhance phosphorus acquisition and sorghum performance on low-phosphorus soils. Plant Physiol. 2014, 166, 659-677. [CrossRef] [PubMed]

11. Wissuwa, M.; Yano, M.; Ae, N. Mapping of QTLs for phosphorus deficiency tolerance in rice (Oryza sativa L.). Theor. Appl. Genet. 1998, 97, 777-783. [CrossRef]

12. Chin, J.H.; Gamuyao, R.; Dalid, C.; Bustamam, M.; Prasetiyono, J.; Moeljopawiro, S.; Wissuwa, M.; Heuer, S. Developing rice with high yield under phosphorus deficiency: Pup1 sequence to application. Plant Physiol. 2011, 156, 1202-1216. [CrossRef] [PubMed]

13. Kumar, J.; Gupta, D.S.; Gupta, S.; Dubey, S.; Gupta, P.; Kumar, S. Quantitative trait loci from identification to exploitation for crop improvement. Plant Cell Rep. 2017, 36, 1187-1213. [CrossRef] [PubMed]

14. Ni, J.; Wu, P.; Senadhira, D.; Huang, N. Mapping QTLs for phosphorus deficiency tolerance in rice (Oryza sativa L.). Theor. Appl. Genet. 1998, 97, 1361-1369. [CrossRef]

15. Ming, F.; Zheng, X.; Mi, G.; He, P.; Zhu, L.; Zhang, F. Identification of quantitative trait loci affecting tolerance to low phosphorus in rice (Oryza Sativa L.). Chin. Sci. Bull. 2000, 45, 520-525. [CrossRef]

16. Hu, B.; Wu, P.; Liao, C.; Zhang, W.; Ni, J. QTLs and epistasis underlying activity of acid phosphatase under phosphorus sufficient and deficient condition in rice (Oryza sativa L.). Plant Soil 2001, 230, 99-105. [CrossRef]

17. Lang, N.T.; Buu, B.C. Mapping QTLs for phosphorus deficiency tolerance in rice (Oryza sativa L.). Omonrice 2006, 14, 1-9.

18. Li, J.Z.; Xie, Y.; Dai, A.Y.; Liu, L.F.; Li, Z.C. Root and shoot traits responses to phosphorus deficiency and QTL analysis at seedling stage using introgression lines of rice. J. Genet. Genom. 2009, 36, 173-183. [CrossRef]

19. Lin, D.Z.; Zhang, Y.J.; Zhang, J.Z.; Luo, L.J.; Dong, Y.J. Mapping of QTL for seedling growth response to phosphorus deficiency in rice (Oryza sativa L.). Genom. App. Biol. 2010, 29, 10-16.

20. Paterson, A.H.; Lander, E.S.; Hewitt, J.D.; Peterson, S.; Lincoln, S.E.; Tanksley, S.D. Resolution of quantitative traits into Mendelian factors by using a complete linkage map of restriction fragment length polymorphisms. Nature 1988, 335, 721-726. [CrossRef] [PubMed]

21. Shimizu, A.; Yanagihara, S.; Kawasaki, S.; Ikehashi, H. Phosphorus deficiency induced root elongation and its QTL in rice (Oryza sativa L.). Theor. Appl. Genet. 2004, 109, 1361-1368. [CrossRef] [PubMed]

22. Su, J.Y.; Xiao, Y.M.; Li, M.; Liu, Q.Y.; Li, B.; Tong, Y.P.; Jia, J.Z.; Li, Z.S. Mapping QTLs for phosphorus-deficiency tolerance at wheat seedling stage. Plant Soil 2006, 281, 25-36. [CrossRef]

23. Zhang, Y.X.; Anis, G.B.; Wang, R.; Wu, W.; Yu, N.; Shen, X.; Zhan, X.D.; Cheng, S.H.; Cao, L.Y. Genetic dissection of QTL against phosphate deficiency in the hybrid rice 'Xieyou9308'. Plant Growth Regul. 2017, 84, 123-133. [CrossRef]

24. Chaubey, C.N.; Senadhira, D.; Gregorio, G.B. Genetic analysis of tolerance for phosphorous deficiency in rice (Oryza sativa L.). Theor. Appl. Genet. 1994, 89, 313-317. [CrossRef] [PubMed]

25. Guo, Z.H.; Ding, P.; He, L.Y.; Xu, C.G. Genetic analysis of agricultural traits in rice related to phosphorus efficiency. Acta Genet. Sin. 2006, 33, 634-641. [CrossRef]

26. Panigrahy, M.; Rao, D.N.; Sarla, N. Molecular mechanisms in response to phosphate starvation in rice. Biotechnol. Adv. 2009, 27, 389-397. [CrossRef] [PubMed]

27. Wissuwa, M.; Wegner, J.; Ae, N.; Yano, M. Substitution mapping of Pup1: A major QTL increasing phosphorus uptake of rice from a phosphorus-deficient soil. Theor. Appl. Genet. 2002, 105, 890-897. [PubMed]

28. Gamuyao, R.; Chin, J.H.; Pariasca, J.; Pesares, P.; Catausan, S.; Dalid, G.C.; Slamet, L.I.; Tecson, M.E.; Wissuwa, M.; Heuer, S. The protein kinase PstolI from traditional rice confers tolerance of phosphorus deficiency. Nature 2012, 488, 535-539. [CrossRef] [PubMed] 
29. De Dorlodot, S.; Forster, B.; Pagès, L.; Price, A.; Tuberosa, R.; Draye, X. Root system architecture: Opportunities and constraints for genetic improvement of crops. Trends Plant Sci. 2007, 12, 474-481. [CrossRef] [PubMed]

30. Mu, P.; Huang, C.; Li, J.X.; Liu, L.F.; Li, Z.C. Yield trait variation and QTL mapping in a DH population of rice under phosphorus deficiency. Acta Agron. Sin. 2008, 34, 1137-1142.

31. Wang, Y.; Sun, Y.J.; Chen, D.Y.; Yu, S.B. Analysis of quantitative trait loci in response to nitrogen and phosphorus deficiency in rice using chromosomal segment substitution lines. Acta Agron. Sin. 2009, 35, 580-587. [CrossRef]

32. Xiang, C.; Ren, J.; Zhao, X.Q.; Ding, Z.S.; Zhang, J.; Wang, C.; Zhang, J.W.; Charles, A.J.; Zhang, Q.; Pang, Y.L.; et al. Genetic dissection of low phosphorus tolerance related traits using selected introgression lines in rice. Rice Sci. 2015, 22, 264-274.

33. Kanbar, A.; Shashidhar, H.E.; Hittalmani, S. Mapping of QTL associated with root and related traits in DH population of rice (Oryza sativa L.). Indian J. Genet. 2002, 62, 287-290.

34. Wang, H.M.; Xu, X.M.; Zhan, X.D.; Zhai, R.R.; Wu, W.M.; Shen, X.H.; Dai, G.X.; Cao, L.Y.; Cheng, S.H. Identification of qRL7, a major quantitative trait locus associated with rice root length in hydroponic conditions. Breed. Sci. 2013, 63, 267-274. [CrossRef] [PubMed]

35. Feng, Y.; Zha, R.R.; Cao, L.Y.; Lin, Z.C.; We, X.H.; Cheng, S.H. QTLs for plant height and heading date in rice under two nitrogen levels. Acta Agron. Sin. 2011, 37, 1525-1532. [CrossRef]

36. Niu, Y.F.; Chai, R.S.; Jin, G.L.; Wang, H.; Tang, C.X.; Zhang, Y.S. Responses of root architecture development to low phosphorus availability: A review. Ann. Bot. 2013, 112, 391-408. [CrossRef] [PubMed]

37. Shimizu, A.; Kato, K.; Komatsu, A.; Motomura, K.; Ikehashi, H. Genetic analysis of root elongation induced by phosphorus deficiency in rice (Oryza sativa L.): Fine QTL mapping and multivariate analysis of related traits. Theor. Appl. Genet. 2008, 117, 987-996. [CrossRef] [PubMed]

38. Obara, M.; Tamura, W.; Ebitani, T.; Yano, M.; Sato, T.; Yamaya, T. Fine-mapping of qRL6.1, a major QTL for root length of rice seedlings grown under a wide range of $\mathrm{NH} 4+$ concentrations in hydroponic conditions. Theor. Appl. Genet. 2010, 121, 535-547. [CrossRef] [PubMed]

39. Zhang, Y.J.; Dong, Y.J.; Zhang, J.Z.; Xiao, K.; Xu, J.L.; Terao, H. Mapping QTLs for deficiency phosphorus response to root-growth of rice seedling. Rice Genet. Newsl. 2010, 25, 36-37.

40. Zhu, J.; Mickelson, S.M.; Kaeppler, S.M.; Lynch, J.P. Detection of quantitative trait loci for seminal root traits in maize (Zea mays L.) seedlings grown under differential phosphorus levels. Theor. Appl. Genet. 2006, 113, 1-10. [CrossRef] [PubMed]

41. Yoshida, S.; Forno, D.A.; Cock, J.H.; Gomez, K.A. Laboratory Manual for Physiological Studies of Rice, 3rd ed.; IRRI: Manila, Philippines, 1976. 